\title{
A Randomized Double-Blind Placebo-Controlled Trial of Lactobacillus reuteri for Chronic Functional Abdominal Pain in Children
}

\author{
Kambiz Eftekhari, ${ }^{1, *}$ Zahra Vahedi, ${ }^{2}$ Mojtaba Kamali Aghdam, ${ }^{2}$ and Diana Noemi Diaz ${ }^{2}$ \\ ${ }^{1}$ Department of Pediatrics, Bahrami Hospital, Tehran University of Medical Sciences, Tehran, IR Iran \\ ${ }^{2}$ Department of Pediatrics, Mousavi Hospital, Zanjan University of Medical Sciences, Zanjan, IR Iran \\ *Corresponding Author: Kambiz Eftekhari, Department of Pediatrics, Bahrami Hospital, Tehran University of Medical Sciences, Tehran, IR Iran. Tel: +98-2173013000, Fax: \\ +98-2177568809, E-mail: k-eftekhari@sina.tums.ac.ir
}

Received 2015 May 30; Revised: August 11, 2015; Accepted 2015 August 22

\begin{abstract}
Background: Functional abdominal pain (FAP) is one of the most common diseases, and large percentages of children suffer from it. Objectives: The purpose of the study was to evaluate the effect of Lactobacillus reuteri in treatment of children with functional abdominal pain.

Patients and Methods: This study was a randomized double-blind placebo-controlled trial. Children aged 4 to 16 years with chronic functional abdominal pain (based on Rome III criteria) were enrolled in the study. They were randomly divided into two groups, one receiving probiotic and the other placebo.

Results: Forty children received probiotic and forty others placebo. There were no significant differences in age, weight, sex, location of pain, associated symptoms, frequency and intensity of pain between the groups. The severity and frequency of abdominal pain in the first month compared to baseline was significantly less and at the end of the second month, there was no significant difference between both groups compared to the end of the first month.

Conclusions: This study showed that the severity of pain was significantly reduced in both groups. There was no significant difference in pain scores between them. The effect of probiotic and placebo can probably be attributed to psychological effect of the drugs.

Keywords: Lactobacillus reuteri, Functional Abdominal Pain, Children
\end{abstract}

\section{Background}

Functional abdominal pain (FAP) is one of the most common diseases, and large percentages of children suffer from it. The prevalence of chronic functional abdominal pain in children is not clear. Some studies showed a prevalence of $9 \%-15 \%$ (1). According to the Rome III criteria, the functional abdominal pain must include all of the following criteria:

1- Persistent or episodic abdominal pain

2- Insufficient criteria for other functional gastrointestinal disorders

3- No evidence of an anatomic, inflammatory, metabolic or malignancy disorders

These criteria should be present at least once per week for at least 2 months prior to diagnosis (2). Existence of FAP in childhood can increase the risk of irritable bowel syndrome (IBS) (3), predictors of psychiatric disorders and other psychosomatic symptoms in adulthood (4). The prevalence of celiac disease (CD] in children with FAP was about two times the normal population (5). Current recommendations for treatment of FAP include: reassuring parents, high-fiber diet, antidepressants and peppermint oil (6). Nowadays the probiotics are a new treatment for FAP. In a review article it was indicated that probiotics are more effective than placebo in the treatment of FAP (7). Probiotics are microorganisms that cause an increased resistance against intestinal pathogenic bacteria. They also prevent bacteria from proliferating in the small intestine and are also immune system modulators (8). Most of the studies have shown that the use of these agents is safe, effective and well-tolerated (9). Most strains of probiotics include Lactobacillus and Bifidobacterium $(10,11)$. Some studies have demonstrated that the number of intestinal Lactobacillus and Bifidobacterium in children with FAP and IBS are decreased (12). Therefore, the use of these microorganisms can be effective in the treatment of FAP.

\section{Objectives}

The purpose of this study was to determine the efficacy of Lactobacillus reuteri (BioGaiaß) for treating chronic functional abdominal pain in children.

Copyright (C) 2015, Growth \& Development Research Center. This is an open-access article distributed under the terms of the Creative Commons Attribution-NonCommercial 4.0 International License (http://creativecommons.org/licenses/by-nc/4.0/) which permits copy and redistribute the material just in noncommercial usages, provided the original work is properly cited. 


\section{Patients and Methods}

This is a randomized double-blind placebo-controlled trial. It was conducted on 80 children aged 4 to 16 years, who visited the gastroenterology clinic of Ayatollah Mousavi hospital in Zanjan from 2012 - 2013 (around 14 months). All 4 - 16 years old children with at least 1 attack of abdominal pain per week during the past 2 months were evaluated for functional abdominal pain (FAP) based on Rome III criteria (2). All parents were given enough information about the study and consent to participation in the project obtained.

Inclusion criterion included:

- All children aged 4 to 16 years with functional abdominal pain (FAP) according to Rome III diagnostic criteria

Exclusion criteria included:

- Having an abdominal pain with known organic cause

- Having a history of abdominal and gastrointestinal surgery

- Having FTT or weight loss more than $5 \%$ of body weight

- Having any abnormal paraclinical finding including complete blood count, urinalysis, stool examination for occult blood, biochemistry, abdominal ultrasound, liver function tests, serum amylase and lipase

- Having a history of drug use in the past 3 months including antidepressants or laxatives

- Having any kind of chronic illness

- Having a history of abdomen blunt trauma

The patients were divided into two groups based on the randomized allocation (computer registration). The first group (case group) was given probiotic from Lactobacillus family and reuteri strain (BioGaia® brand manufactured by Sweden health care company) 5 drops per day orally equivalent to $108 \mathrm{CFU}$ (Colony-Forming Units) for 4 weeks. The second group (control group) received placebo for the same period. The physicians and the patients were unaware of the contents of the medications prescribed (double blind study). The drugs were discontinued after 4 weeks. Patients were followed up for 4 weeks after cessation of treatment. In follow up period frequency and severity of pain, other symptoms and drug side effects were carefully recorded.

Demographic data and pain characteristics (frequency, location, presence or absence of associated symptoms, need to sedative for pain relief) were recorded. Pain intensity was assessed according to the Wong-Baker faces scale system (Figure 1) (13). The scale includes six face images showing the effect of the pain, ranging from relax face (no pain) in the left side and intense face (most severe pain) in the right side. It is scored from 0 to 5 . During follow up the researcher assessed intensity pain scores, frequency of pain, and ultimately response to treatment.

Finally the data were analyzed with SPSS software and using descriptive statistics, the frequency distribution chart, Chi-square test and relative risk was calculated. In all stages of the analysis, P-value equal or less than 0.05 (P-Value $\leq 0.05$ ) was considered statistically significant.

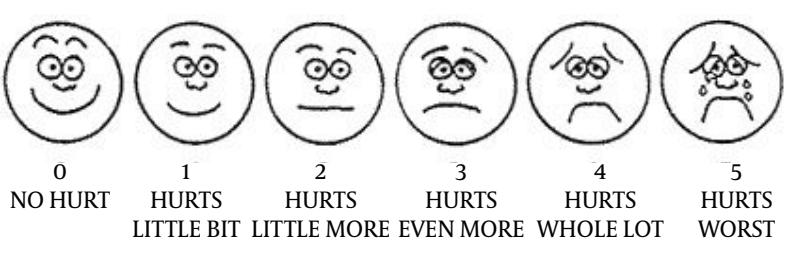

Figure 1. Wong-Baker Faces Scale System for Evaluation of Abdominal Pain Intensity in Children

The study was approved by the ethical committee of Zanjan university of medical sciences. Registry code in a clinical trial registry center (IRCT) is IRCT2014083018971N1.

\section{Results}

During a 14-month study, 270 children with abdominal pain were referred to the pediatrics gastroenterology clinic. Of these, only 80 children fulfilled the criteria of functional abdominal pain (Rome III), which were divided into two groups. Forty children were in the case group (BioGaia® recipient group) half of whom were boys. Other children (40 cases) were in the control group (placebo recipient group), $52.5 \%$ of these were males and $47.5 \%$ females. The mean and standard deviation of age in the case and control group were $6.26 \pm 2.10$ and $6.26 \pm 2.61$ years, respectively. $(\mathrm{P}=0.16)$. There was no statistically significant difference in terms of mean and standard deviation of weight (Table 1$)(\mathrm{P}=0.99)$. At baseline $97.5 \%$ of children in case group and $90 \%$ of the control group did not have any associated symptoms. However, constipation was seen in $2.5 \%$ of children in case group. Fever and anorexia were seen in $2.5 \%$ and $7.5 \%$ of children in control group, respectively. In this sense, both groups were consistent $(P$ $=0.16$ ), $95 \%$ of patients in the case group and $97.5 \%$ in the control group had periumbilical pain, and the remaining had hypogastric pain. $(P=0.55)$. At initiation of the study, intensity of abdominal pain in the case group according to scoring system of Wong-Baker faces scale was about 30\% More, 57.7\% Even More and 12.5\% Whole. In the control group it was 22.5\% More, 50\% Even More and 27.5\% Whole. In this sense, there was no significant difference between the groups (Table 2). At the end of the second month, 40\% in case group and 65\% in control group were No Hurt. Again, no significant difference was found between the groups (Table 2).

Table 1. Comparison of Mean and Standard Deviation of Age and Weight in Children at Two Study Groups

\begin{tabular}{|c|c|c|c|}
\hline \multirow[t]{2}{*}{ Variables } & \multicolumn{2}{|c|}{ Group } & \multirow[t]{2}{*}{ P-Value } \\
\hline & Case & Control & \\
\hline Age & $6.26 \pm 2.10$ & $6.26 \pm 2.61$ & 0.16 \\
\hline Weight & $20.86 \pm 5.24$ & $22.71 \pm 10.30$ & 0.87 \\
\hline
\end{tabular}


Wong-Baker faces scale has 6 scores for comparison of abdominal pain intensity.

Zero score is used for No Hurt and 6 for Whole. Applying this scoring system, average score obtained in the control group at baseline was $4.05 \pm 0.71$, at the end of first month $2.08 \pm 1.56$ and at the of second month $2.25 \pm 1.46$. In the case group corresponding scores were $3.83 \pm 0.63,2.50$ \pm 1.45 and $2.53 \pm 1.43$, respectively. According to these results, there was significant difference between the groups at baseline and first month after treatment $(\mathrm{P}=0.0001)$, while there was no significant difference at the end of second and first month in both groups (In case group $\mathrm{P}$ $=0.317$ and control group $\mathrm{P}=0.227$ ). At first month, 50\% of children in case group and 65\% in control group had no pain and at second month $47.5 \%$ in case group and $52.5 \%$ in control group did not report any pain. In this respect, there were no statistically significant differences between the groups (Table 3). Average pain episodes per week in the control group was $1.33 \pm 0.47$ at baseline, 0.40 \pm 0.59 at first month and $0.53 \pm 0.59$ at second month. In the case group it was $1.45 \pm 0.55$ at baseline, $0.68 \pm 0.76$ at first month and $0.70 \pm 0.75$ at second month. Here also, there was a significant change in both groups compared to the first month $(\mathrm{P}=0.0001)$, but the change was not significant in the second month compared with the first month (In case group $\mathrm{P}=0.317$ and control group $\mathrm{P}=$ 0.059). Lactobacillus reuteri was well tolerated and did not have any adverse reactions.

Table 2. Comparison of Abdominal Pain Intensity Based on Wong-Baker Scale System Between the Two Groups Before and After the First and Second Month

\begin{tabular}{|c|c|c|c|c|c|c|}
\hline \multirow[t]{2}{*}{ Time/Groups } & \multicolumn{5}{|c|}{ Pain Intensity } & \multirow[t]{2}{*}{ P-Value } \\
\hline & No Hurt & Little & More & Even More & Whole & \\
\hline Baseline & & & & & & 0.44 \\
\hline Case & $0(0)$ & $0(0)$ & $12(30)$ & $23(57.5)$ & $5(12.5)$ & \\
\hline Control & $0(0)$ & $0(0)$ & $9(22.5)$ & $20(50)$ & $11(12.5)$ & \\
\hline End of the first month & & & & & & 0.16 \\
\hline Case & $16(40)$ & $5(12.5)$ & $5(12.5)$ & $11(27.5)$ & $3(7.5)$ & \\
\hline Control & $26(65)$ & $0(0)$ & $2(5)$ & $9(22.5)$ & $9(22.5)$ & \\
\hline End of the second month & & & & & & 0.20 \\
\hline Case & $15(37.5)$ & $6(15)$ & $5(12.5)$ & $11(27.5)$ & $3(7.5)$ & \\
\hline Control & $21(52.5)$ & $2(5)$ & $6(15)$ & $8(20)$ & $3(7.5)$ & \\
\hline
\end{tabular}

\begin{tabular}{|c|c|c|c|c|c|}
\hline \multirow[t]{2}{*}{ Time/Group } & \multicolumn{4}{|c|}{ Pain Episodes per Week } & \multirow[t]{2}{*}{ P-Value } \\
\hline & No Pain & $1-3$ & $3-6$ & $6-9$ & \\
\hline Baseline & & & & & 0.44 \\
\hline Case & $0(0)$ & $23(57.5)$ & $16(40)$ & $1(2.5)$ & \\
\hline Control & $0(0)$ & $27(67.5)$ & $13(32.5)$ & $0(0)$ & 0.16 \\
\hline \multicolumn{6}{|c|}{ End of the first month } \\
\hline Case & $20(50)$ & $13(32.5)$ & $7(17.5)$ & $0(0)$ & 0.20 \\
\hline Control & $26(65)$ & $12(30)$ & $2(5)$ & $0(0)$ & \\
\hline \multicolumn{6}{|c|}{ End of the second month } \\
\hline Case & $19(47.5)$ & $14(35)$ & $7(17.5)$ & $0(0)$ & \\
\hline Control & $21(52.5)$ & $17(42.5)$ & $2(5)$ & $0(0)$ & \\
\hline
\end{tabular}




\section{Discussion}

This study investigated the effects of Lactobacillus reuteri and placebo in reducing severity and frequency of pain in 80 children aged 4 to 16 years with chronic functional abdominal pain. Functional gastrointestinal disorders (FGID) are one of the most common childhood disorders, pathophysiology of which is still not well defined (14). Number of Intestinal flora plays an important role in creating this problem. Some of the studies have shown that the number of Lactobacillus is significantly reduced in the intestine of these patients $(15,16)$. Thus, replacement of these microorganisms was an acceptable hypothesis for treatment of functional abdominal pain. In our study both cases and control groups in terms of age, sex, weight, number of pain episodes per week, location of pain and associated symptoms were consistent. After treatment, the pain was significantly reduced in both groups. However, there was no significant difference between the groups in the intensity and frequency of pain episodes. After one month of cessation of drugs, no significant change was observed compared to the first month. Our study revealed that use of probiotics in treating FAP had no preference to placebo. In literature reports regarding the effect of Lactobacillus reuteri in the treatment of FAP, there is a parallel study and a contrary to our study. Niv et al. as in our study, found that the effect of Lactobacillus reuteri was similar to placebo in reducing abdominal pain and no more than that (17). Unlike our study, Claudio Romano et al reorted that Lactobacillus reuteri reduces the severity of pain in children but, similar to our results does not reduce the frequency of pain (18). There are very little studies in this field on children. The dose of probiotic was chosen based on previous published studies (19), its manufacturer's recommendations (109 CFU) and duration of treatment as mentioned in the literature (20). However, the optimal dose and duration of drug therapy in the treatment of FAP is not clearly identified yet. In this study, we treated the samples randomly divided into two groups, so that the groups were matched for age and sex. We used an appropriate control group and our study was double-blinded. The main limitation of our study was the little number of samples. Other limitation of the study was not having access to patients over 13 years old. Most of them were referred to the adults' gastroenterology clinic and could not be included in the study. So, average age of the patients in our study was considered lower than that in other studies.

To achieve appropriate management of FAP many evaluations are required. Our results showed that, although Lactobacillus reuteri may be effective in reducing severity and frequency of pain, its effect is not greater than placebo. Again our study proved that the use of placebo in the treatment of functional gastrointestinal disorders can be helpful, which emphasizes the fact that main causes of the disorder are mental and emotional problems, and also environmental stress, whereas the organic causes are less involved.
The major contribution to the treatment of FAP is to ensure the child and parents, so stress could be reduced. Pharmacologic therapy with placebo or other drugs, can lead to increased confidence.

\section{Acknowledgments}

We are grateful to all of the children and their families who generously volunteered their time and knowledge in this study.

\section{Footnote}

Funding/Support:Financial support was provided by vice chancellor for research of Zanjan university of medical sciences.

\section{References}

1. Sreedharan R, Chris A. Functional abdominal pain (non organic chronic abdominal pain. In: Stanton K, Geme S, Behrman S, editors. Nelson Text Book of Pediatrics. Elsevier; 2011. pp. 1643-6.

2. Helgeland H, Flagstad G, Grøtta J, Vandvik P, Kristensen H, Markestad T. Diagnosing Pediatric Functional Abdominal Pain in Children (4-15 Years Old) According to the Rome III Criteria: Results From a Norwegian Prospective Study. J Pediatr Gastroenterol Nutr. 2009;49(3):309-15. doi:10.1097/MPG.0b013e31818de3ab. [PubMed:19525874]

3. Perquin CW, Hunfeld JA, Hazebroek-Kampschreur AA, Suijlekom-Smit LW, Passchier J, Koes BW, et al. The natural course of chronic benign pain in childhood and adolescence: a two-year population-based follow-up study. Eur J Pain. 2003;7(6):551-9. doi: 10.1016/s1090-3801(03)00060-0. [PubMed:14575668]

4. Achenbach TM, McConaughy SH, Howell CT. Child/adolescent behavioral and emotional problems: implications of crossinformant correlations for situational specificity. Psychol Bull. 1987;101(2):213-32. [PubMed:3562706]

5. Farahmand F, Modaresi V, Najafi M, Khodadad A, Moetamed F, Modarres Z. Prevalence of celiac disease in Iranian children with recurrent abdominal pain referred to a pediatric referral center Iran J Pediatr. 2011;21(1):33-8. [PubMed: 23056761]

6. Jee SR, Jung HK, Min BH, Choi KD, Rhee PL, Kang YW, et al. [Guidelines for the treatment of functional dyspepsia]. Korean J Gastroenterol. 2011;57(2):67-81. [PubMed: 21350319]

7. Korterink JJ, Ockeloen L, Benninga MA, Tabbers MM, Hilbink M, Deckers-Kocken JM. Probiotics for childhood functional gastrointestinal disorders: a systematic review and meta-analysis. Acta Paediatr. 2014;103(4):365-72. doi: 10.1111/apa.12513. [PubMed: 24236577]

8. Szajewska H. Prebiotics, synbiotics and fermented products. In: Kleinman RE, Sanderson IR, Goulet O, editors. Walker's Pediatric Gastrointestinal Disease. 5th ed ed. Decker: Hamilton; 2008. pp. 399-409.

9. Jafari E, Vahedi H, Merat S, Momtahen S, Riahi A. Therapeutic effects, tolerability and safety of a multi-strain probiotic in Iranian adults with irritable bowel syndrome and bloating. Arch Iran Med. 2014;17(7):466-70. [PubMed:24979556]

10. Horvath A, Szajewska H. Probiotics, prebiotics, and dietary fiber in the management of functional gastrointestinal disorders. World Rev Nutr Diet. 2013;108:40-8. doi: 10.1159/000351483. [PubMed: 24029785]

11. Demers M, Dagnault A, Desjardins J. A randomized doubleblind controlled trial: Impact of probiotics on diarrhea in patients treated with pelvic radiation. Clin Nutr. 2014;33(5):761-7. doi:10.1016/j.clnu.2013.10.015. [PubMed: 24200199]

12. Horvath A, Dziechciarz P, Szajewska H. Meta-analysis: Lactobacillus rhamnosus GG for abdominal pain-related functional gastrointestinal disorders in childhood. Aliment Pharmacol Ther. 2011;33(12):1302-10. doi:10.1111/j.1365-2036.2011.04665.x. [PubMed: 
21507030]

13. Bieri D, Reeve RA, Champion DG, Addicoat L, Ziegler JB. The faces pain scale for the self-assessment of the severity of pain experienced by children: Development, initial validation, and preliminary investigation for ratio scale properties. Pain. 1990;41(2):13950. doi:10.1016/0304-3959(90)90018-9. [PubMed: 2367140]

14. Saps M, Lu P, Bonilla S. Cow's-milk allergy is a risk factor for the development of FGIDs in children. J Pediatr Gastroenterol Nutr. 2011;52(2):166-9. doi: 10.1097/MPG.0b013e3181e85b55. [PubMed: 20975580]

15. Marshall JK, Thabane M, Garg AX, Clark WF, Moayyedi P, Collins SM, et al. Eight year prognosis of postinfectious irritable bowel syndrome following waterborne bacterial dysentery. Gut. 2010;59(5):605-11. doi: 10.1136/gut.2009.202234. [PubMed: 20427395]

16. Wilhelm SM, Brubaker CM, Varcak EA, Kale-Pradhan PB. Effectiveness of probiotics in the treatment of irritable bowel syndrome. Pharmacotherapy. 2008;28(4):496-505. doi: 10.1592/ phco.28.4.496. [PubMed:18363533]
17. Niv E, Naftali T, Hallak R, Vaisman N. The efficacy of Lactobacillus reuteri ATCC 55730 in the treatment of patients with irritable bowel syndrome--a double blind, placebo-controlled, randomized study. Clin Nutr. 2005;24(6):925-31. doi: 10.1016/j. clnu.2005.06.001. [PubMed:16051399]

18. Romano C, Ferrau V, Cavataio F, Iacono G, Spina M, Lionetti E, et al. Lactobacillus reuteriin children with functional abdominal pain (FAP). J Paediatr Child Health. 2014;50(10):E68-71. doi: 10.1111/j.1440-1754.2010.01797.x. [PubMed: 20626584]

19. Gawronska A, Dziechciarz P, Horvath A, Szajewska H. A randomized double-blind placebo-controlled trial of Lactobacillus GG for abdominal pain disorders in children. Aliment Pharmacol Ther. 2007;25(2):177-84. doi: 10.1111/j.1365-2036.2006.03175.x. [PubMed:17229242]

20. Design of Treatment Trials C, Irvine EJ, Whitehead WE, Chey WD, Matsueda K, Shaw M, et al. Design of treatment trials for functional gastrointestinal disorders. Gastroenterology. 2006;130(5):153851. doi:10.1053/j.gastro.2005.11.058. [PubMed:16678567] 